\title{
Collision Scenarios and Probabilistic Collision Damage
}

\author{
Alan J. Brown \\ Virginia Polytechnic Institute and State University, Department of Aerospace and Ocean Engineering
}

\begin{abstract}
This paper examines the influence of collision scenario random variables on the extent of predicted damage in ship collisions. Struck and striking ship speed, collision angle, striking ship type and striking ship displacement are treated as independent random variables. Other striking ship characteristics are treated as dependent variables derived from the independent variables based on relationships developed from worldwide ship data. A simplified collision model (SIMCOL) is used to assess the sensitivity of probabilistic damage extent to these variables. SIMCOL applies the scenario variables directly in a time-stepping simultaneous solution of internal (structural) and external (ship) problems vice an uncoupled solution of these problems. During the simultaneous solution SIMCOL also calculates struck ship absorbed energy in the longitudinal and transverse directions. These results are compared to absorbed energy estimated based on uncoupled external dynamics only. The necessity and effectiveness of this approach is examined.
\end{abstract}




\section{MOTIVATION AND INTRODUCTION}

The serious consequences of ship collisions necessitate the development of regulations and requirements for the subdivision and structural design of ships to minimize damage, reduce environmental pollution, and improve safety. The Society of Naval Architects and Marine Engineers (SNAME) Ad Hoc Panel \#6 was established to study the effect of structural design on the extent of damage in ship collision and grounding. SNAME and the Ship Structure Committee (SSC) sponsor research under this panel as reported by Sirkar et al. (1997), Crake (1995), Rawson et al. (1998), Chen (2000), and Brown et al. (2000). A Simplified Collision Model (SIMCOL) was developed as part of this research. It is used in a Monte Carlo simulation as described by Brown (1996) to predict probabilistic damage. Preliminary results from this research are presented in this paper.

The collection of collision and collision scenario data is an essential element in this development. Collision data is required for two purposes:

- Collision model validation

- Definition of probabilistic collision scenarios

These two data requirements are very different. This paper considers only the analysis of data to define probabilistic collision scenarios.

Thousands of cases are required to develop probabilistic descriptions of possible collision scenarios. For a given struck ship design, the collision scenario is defined probabilistically using random variables. Collision angle, strike location, and ship speed data must be collected from actual collision events or developed using a ship encounter model. Striking ship data may come from actual collision events, local or regional models or worldwide ship characteristics.

This paper provides a preliminary set of probabilities, probability density functions and equations required to generate specific collision scenarios in a Monte Carlo simulation using SIMCOL. It assesses the sensitivity of structural damage (penetration and length) to each of these independent variables applied in ten thousand collision scenarios with each of four different struck ships, and it assesses the necessity of solving the internal damage problem simultaneously with the external ship dynamics.

\section{SIMCOL}

SIMCOL uses a time-domain simultaneous solution of external ship dynamics and internal deformation mechanics similar to that originally proposed by Hutchison (1986).

SIMCOL Version 0.0 was developed as part of the work of SNAME Ad Hoc Panel \#3. Based on further research, test runs and the need to make the model sensitive to a broader range of design and scenario variables, improvements were made progressively at Virginia Tech. A sweeping segment method was added to the model in SIMCOL Version 1.0 to improve the calculation of damage volume and the direction of damage forces. Models from work by Rosenblatt (1975) and McDermott (1974) were applied in Version 1.1 assuming rigid web frames. In Version 2.0, the lateral deformation of web frames was included. In Version 2.1, the vertical extent of the striking ship bow is considered. Table 1 summarizes the evolution of SIMCOL over the last five years. Version 2.1 is used for the research presented in this paper and is described in the following sections.

Table 1 - SIMCOL Evolution

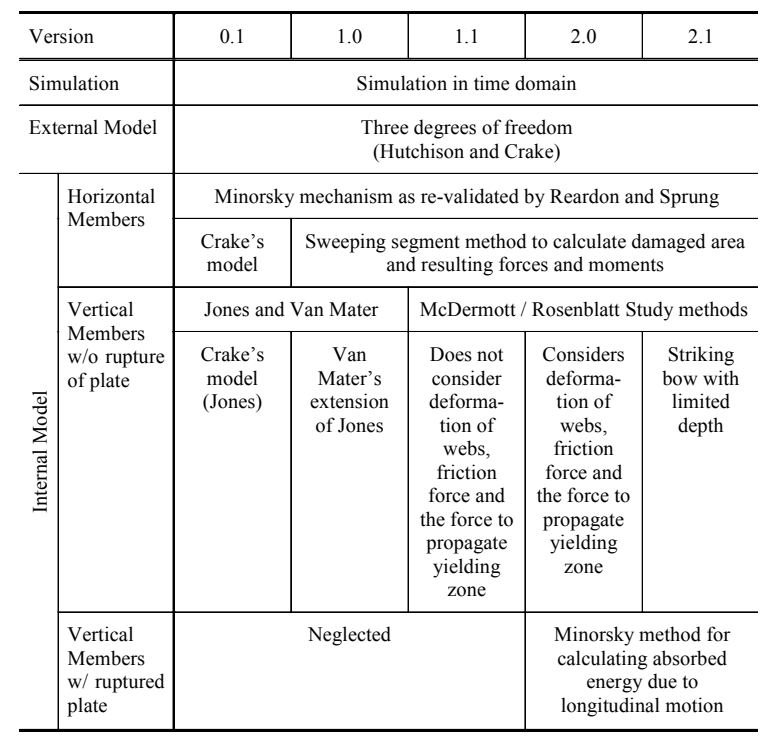

\subsection{SIMCOL External Dynamics Sub-Model}

Figure 1 shows the SIMCOL simulation process. The Internal Sub-Model performs Steps 2 and 3 in this process. It calculates internal deformation due to the relative motion of the two ships, and the internal reaction forces resulting from this deformation. The External Sub-Model performs Steps 1 and 4 in this process. A summary of the External Sub-Model is provided in this section.

The External Dynamics Sub-Model uses a global coordinate system shown in Figure 2. Its origin is at the initial $(\mathrm{t}=0)$ center of gravity of the struck ship with the $x$-axis towards the bow of the struck ship. The initial locations and orientations of the struck 
and striking ships in the global coordinate system are:

$$
\begin{aligned}
& x_{1,0}=0 \quad y_{1,0}=0 \quad \theta_{1,0}=0 \\
& x_{2,0}=-l_{0}+\frac{L_{B P 2}}{2} \cos \phi_{0} \\
& y_{2,0}=\frac{B_{1}}{2}+\frac{L_{B P 2}}{2} \sin \phi_{0} \\
& \theta_{2,0}=\phi_{0}-\pi
\end{aligned}
$$

where:

$x_{1}, y_{1}-$ center of gravity of the struck ship (m)

$\theta_{1} \quad$ - heading of the struck ship (degrees)

$x_{2}, y_{2}$ - center of gravity of the striking ship (m)

$\theta_{2}$ - heading of the striking ship

$L_{B P 2}$ - LBP of the striking ship (m)

$B_{1} \quad$ - breadth of the struck ship (m)

$\phi \quad$ - collision angle (degrees)

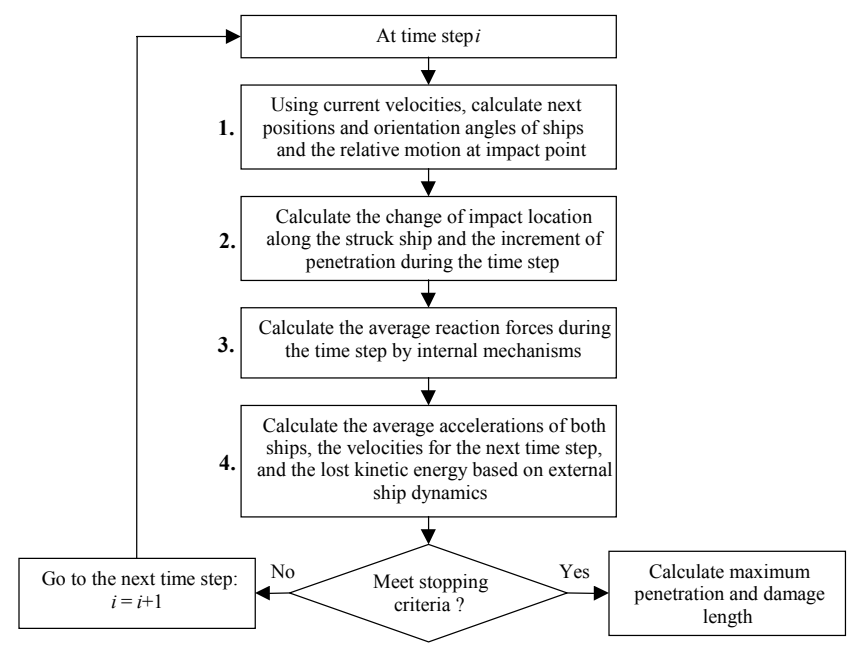

Figure 1 - SIMCOL Simulation Process

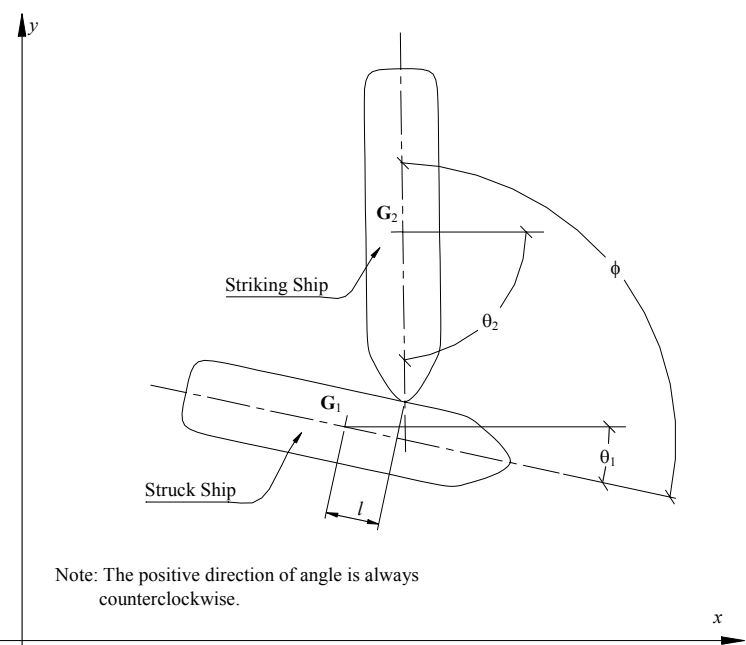

Figure 2 - SIMCOL Global Coordinate System

A local damage coordinate system, $\xi-\eta$, is established on the struck ship to calculate relative movement and collision forces. The origin of this system is set at midship on the shell plate of the damaged side of the struck ship. Axes $\xi$ and $\eta$ point aft and inboard relative to the struck ship. Local coordinate systems are also established at the centers of gravity of both struck and striking ships. Forces and moments in the local systems are transformed to the global $x-y$ system for solution of the ship dynamics.

Considering the symmetry of the ships, and with the center of gravity of the ships assumed at midship, the local system added mass tensor for each ship is:

$\mathbf{A}_{s}=\left[\begin{array}{ccc}a_{11} & 0 & 0 \\ 0 & a_{22} & 0 \\ 0 & 0 & a_{33}\end{array}\right]$

where:

$a_{11} \quad$ - added mass in the surge direction $(\mathrm{kg})$

$a_{22} \quad$ - added mass in the sway direction $(\mathrm{kg})$

$a_{33}$ - yaw added mass moment of inertia $\left(\mathrm{kg}-\mathrm{m}^{2}\right)$

The added mass tensor is transformed in accordance with the orientation of each ship to the global coordinate system. The transformed tensor, $\mathbf{A}_{\theta}$, for each ship is:

$\mathbf{A}_{\theta}=\left[\begin{array}{ccc}a_{11} \cos ^{2} \theta+a_{22} \sin ^{2} \theta & \left(a_{11}-a_{22}\right) \cos \theta \sin \theta & 0 \\ \left(a_{11}-a_{22}\right) \cos \theta \sin \theta & a_{11} \sin ^{2} \theta+a_{22} \cos ^{2} \theta & 0 \\ 0 & 0 & a_{33}\end{array}\right]$

The mass for each ship is represented by a tensor:

$\mathbf{M}_{\text {ship }}=\left[\begin{array}{ccc}m_{s} & 0 & 0 \\ 0 & m_{s} & 0 \\ 0 & 0 & I_{s 33}\end{array}\right]$

where:

$m_{s}$ - mass of each ship (kg)

$I_{s 33}$ - yaw mass moment of inertia $\left(\mathrm{kg}-\mathrm{m}^{2}\right)$

The virtual mass, $\mathbf{M}_{V}$, for each ship is:

$$
\begin{aligned}
& \mathbf{M}_{V \theta}=\mathbf{M}_{s h i p}+\mathbf{A}_{\theta}=\left[\begin{array}{ccc}
m_{V 11} & m_{V 12} & 0 \\
m_{V 21} & m_{V 22} & 0 \\
0 & 0 & I_{V 33}
\end{array}\right] \\
& =\left[\begin{array}{ccc}
m_{s}+a_{11} \cos ^{2} \theta+a_{22} \sin ^{2} \theta & \left(a_{11}-a_{22}\right) \cos \theta \sin \theta & 0 \\
\left(a_{11}-a_{22}\right) \cos \theta \sin \theta & m_{s}+a_{11} \sin ^{2} \theta+a_{22} \cos ^{2} \theta & 0 \\
0 & 0 & I_{s 33}+a_{33}
\end{array}\right]
\end{aligned}
$$

Referring to Figure 2, Step 1, the velocities from the previous time step are applied to the ships to calculate their positions at the end of the current time step:

$\mathbf{X}_{n+1}=\mathbf{X}_{n}+\mathbf{V}_{s n} \tau$

where:

$\mathbf{X}$ - location and orientation of ships in the global system, $\mathbf{X}=\{x, y, \theta\}^{T}$

$\mathbf{V}_{s n}-$ ship velocity, $\mathbf{V}_{s}=\{u, v, \omega\}^{T}$

$\tau$ - time step (seconds)

In Steps 2 and 3, the Internal Model calculates the compatible deformation, and the average forces and moments generated by this deformation over the time step. In Step 4, these forces and moments are 
applied to each ship. The new acceleration for each ship is:

$\mathbf{V}_{\mathbf{s}}^{\prime}=\frac{\mathbf{F}}{\mathbf{M}_{V \vartheta}}$

$u^{\prime}=\frac{F_{x} m_{V 22}-F_{y} m_{V 12}}{m_{V 11} m_{V 22}-m_{V 12}^{2}}$

$v^{\prime}=\frac{F_{y} m_{V 11}-F_{x} m_{V 12}}{m_{V 11} m_{V 22}-m_{V 12}^{2}}$

$\omega^{\prime}=\frac{M}{I_{V 33}}$

where:

F - forces exerted on the ships in the global system, $\mathbf{F}=\left\{F_{x}, F_{y}, M\right\}^{T}$

$\mathbf{V}_{s}^{\prime}$ - ship acceleration, $\mathbf{V}_{s}^{\prime}=\left\{u^{\prime}, v^{\prime}, \omega^{\prime}\right\}^{T}$

The new velocity for each ship at the end of the time step is then:

$$
\mathbf{V}_{s, n+1}=\mathbf{V}_{s, n}+\mathbf{V}_{s}^{\prime} \tau
$$

\subsection{SIMCOL Internal Sub-Model}

The Internal Sub-Model calculates the struck ship deformation resulting from the ships' relative motion, and calculates the average internal forces and moments generated by this deformation over the time step. Refer to Figure 1, Steps 2 and 3. The Internal Sub-Model determines reacting forces from side and bulkhead (vertical) structures using specific component deformation mechanisms including: membrane tension; shell rupture; web frame bending; shear and compression; force required to propagate the yielded zone; and friction. It determines absorbed energy and forces from the crushing and tearing of decks, bottoms and stringers (horizontal structures) using the Minorsky (1959) correlation as modified by Reardon and Sprung (1996). Total forces are the sum of these two components. In SIMCOL Version 2.1, the striking ship bow is assumed to be rigid and wedge-shaped with upper and lower extents determined by the bow height of the striking ship and the relative drafts of the two ships. Deformation is only considered in the struck ship.

Penetration of the struck ship begins with the side shell plating and webs (vertical structures). Figure 3 illustrates the two basic types of strike determined by the strike location relative to the webs. In this analysis:

- Plastic bending of shell plating is not considered. The contribution of plastic bending in the transverse deformation of longitudinally stiffened hull plates is negligible. The sample calculation sheets in Rosenblatt (1975) support this argument. In six test cases, the energy absorbed in plastic bending never exceeds $0.55 \%$ of the total absorbed energy when the cargo boundary is ruptured. It is a good assumption that the plastic membrane tension phase starts from the beginning of collision penetration and is the primary shell energy-absorption mechanism.

- Rupture of stiffened hull plates starting in the stiffeners is not considered. This mechanism is unlikely for most structures except for flat-bar stiffened plates. It is a standard practice to use angles or bulbs instead of flat bar for longitudinal stiffeners of side shell and longitudinal bulkheads, therefore, this option is not considered in SIMCOL.

- Web frames do not yield or buckle before plates load in membrane tension. McDermott (1974) demonstrates that this mechanism is unlikely and does not contribute significantly to absorbed energy in any case. This mechanism requires very weak web frames that would not be sufficient to satisfy normal sea and operational loads.

SIMCOL Version 1.1 assumes that flanking web frames are rigid. Version 2.0 and subsequent versions used for this paper consider the transverse deformation of webs.

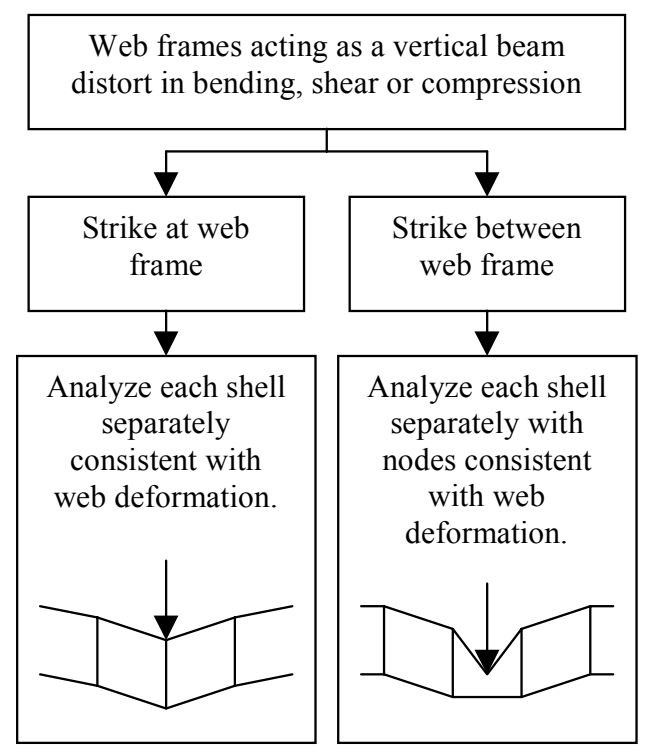

Figure 3 - Web Deformation in SIMCOL 2.0

In a right-angle collision case, Equation (10) gives the total plastic energy absorbed in membrane tension in time step $n$. This assumes that the plate is not ruptured, that flanking webs do not deflect in the longitudinal direction, and that compression in the side shell caused by longitudinal bending of the ship hull girder is small. 
$E_{n}=T_{m} e_{t n}$

$T_{m}=\sigma_{m} t B_{e}$

where:

$E_{n}$ - plastic energy absorbed by side shell or longitudinal bulkhead (J)

$T_{m}$ - membrane tension (N)

$\sigma_{m}$ - yield stress of side shell or bulkhead adjusted for strain rate $(\mathrm{Pa})$

$e_{t n}$ - total elongation of shell or bulkhead structure within the damaged web spacing

$t \quad$ - smeared thickness of side shell or bulkhead

plating and stiffeners $(\mathrm{m})$

$B_{e}$ - effective breadth (height) of side shell or bulkhead (m)

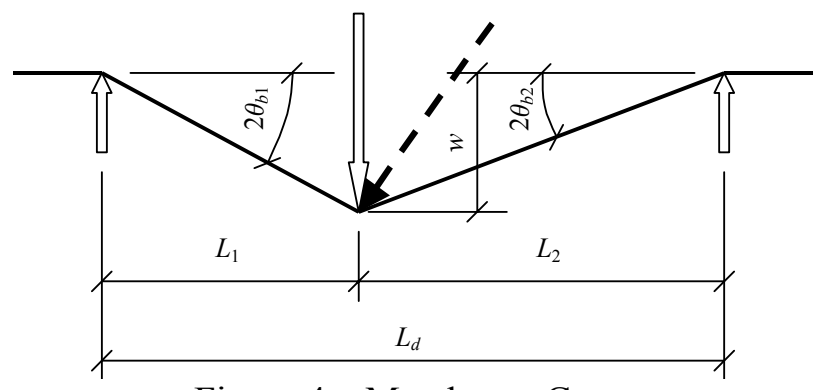

Figure 4 - Membrane Geometry

Figure 4 illustrates the membrane geometry for calculation of elongation where $e_{1}$ and $e_{2}$ are the elongation of legs $L_{1}$ and $L_{2}$ respectively:

$e_{i}=\sqrt{L_{i}^{2}+w^{2}}-L_{i} \cong \frac{w^{2}}{2 L_{i}}$

$e_{t}=e_{1}+e_{2}=\frac{L_{d}}{2 L_{1} L_{2}} w^{2}$

and:

$L_{d}$ - distance between adjacent webs (m)

$w_{n}-$ transverse deflection at time step $n(\mathrm{~m})$

Side shell rupture due to membrane tension is predicted using the following criteria:

- The strain in the side shell reaches the rupture strain, $\epsilon_{r}$, which is taken as $10 \%$ in ABS steel; or

- The bending angle at a support reaches the critical value as defined in Equation (12).

$\varepsilon_{m}=\frac{4}{3} \frac{\sigma_{m}}{\sigma_{u}-\sigma_{m} \cos \theta_{c}} \sin \theta_{c} \tan \theta_{c}=1.5 D$

where:

$\epsilon_{m}$ - maximum bending and membrane-tension

strain to rupture

$\sigma_{m^{-}}$membrane-tension in-plate stress (MPa)

$\sigma_{u}-$ ultimate stress of the plate (MPa)

$\theta_{c}$ - critical bending angle

$D$ - tension test ductility
The resistance of the membrane is only considered up to the point of rupture:

$\varepsilon_{i}=\frac{e_{i}}{L_{i}} \leq \varepsilon_{r}$

$\theta_{b i}=\frac{1}{2} \arctan \frac{w}{L_{i}} \cong \frac{w}{2 L_{i}} \leq \theta_{c}$

where:

$\epsilon_{i}-$ strain in leg $i$

$\theta_{b i}$ - bending angle of flanking web frames

Since the striking bow normally has a generous radius, the bending angle at the impact location is not considered in the rupture criteria. From these equations, it is seen that only the strain and bending angle in the shorter leg need be considered for right angle collisions. Based on material properties of ABS steel, the critical bending angle $\theta_{c}$ from Equation (12) is $19.896,17.318$ or 16.812 degrees for MS, H32 or H36 grades respectively. Once either of the rupture criteria is reached, the side shell or longitudinal bulkhead is considered ruptured and does not continue to contribute to the reacting force.

For collisions at an oblique angle, the membrane tension is only fully developed in the leg behind the strike, $L_{2}$ in Figure 4. This is demonstrated in the force diagram shown in Figure 5, where $T_{1}$ is much smaller than $T_{2}$. It is also assumed that all the strain developed from membrane tension is behind the striking point. Therefore, the first rupture criterion in Equation (13) becomes:

$\varepsilon_{b}=\frac{e_{t}}{L_{b}} \leq \varepsilon_{r}$

where $\epsilon_{b}$ and $L_{b}$ represent the strain and length of the leg behind the striking. In Figure 4, they are $\epsilon_{2}$ and $L_{2}$, respectively.

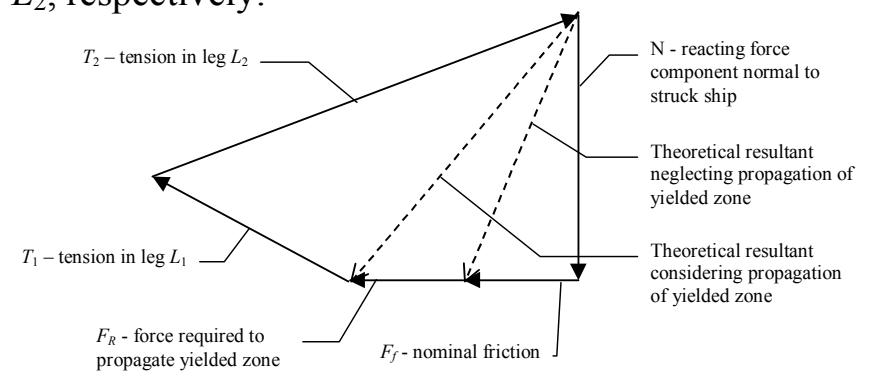

Figure 5 - Oblique Collision Force Diagram

In SIMCOL Version 2.0 and later, transverse deformation of web frames is also considered. Web failure modes include bending, shear, and compression. Web frames are allowed transverse deformation while keeping their longitudinal locations. The resisting force is assumed constant at a distorted flanking web frame, and the transverse deformation of the web frame is assumed uniform from top to bottom. The magnitude of this force is 
its maximum elastic capacity. From Figure 5, the applied force on a rigid flanking web frame is:

$P_{i}=T_{i} \frac{w}{L_{i}}$

where $P_{i}$ and $T_{i}$ are referred to the particular leg $L_{i}$. If the applied force, $P_{i}$, is greater than the maximum elastic capacity of the flanking web, $P_{w f}$, the particular web frame is deformed as shown in Figure 6. The change of angle, $\gamma_{c}$, at the distorted web is then:

$\gamma_{c i} \cong \frac{P_{w f}}{T_{i}}$

Rosenblatt (1975) proposed an approach to determine whether $P_{i}$ exceeds the capacity $P_{w f}$, and to estimate the value of $P_{w f}$. First, the allowable bending moment and shear force of the web frame at each support, the crushing load of the web, and the buckling force of supporting struts are calculated. Then, the load $P_{i}$ is applied to the web frame, and the induced moments, shear forces and compression of the web frame and struts are calculated, considering the web frame as a beam with clamped ends. The ratios of the induced loads to the allowable loads are determined using Equation (17). If the maximum ratio, $R_{m}$, is greater than unity, the load, $P$, exceeds the capacity, and the web frame deforms. $R_{m}$ is also used to estimate the number of distorted web frames.

$R_{m}=\frac{P}{P_{w f}}$

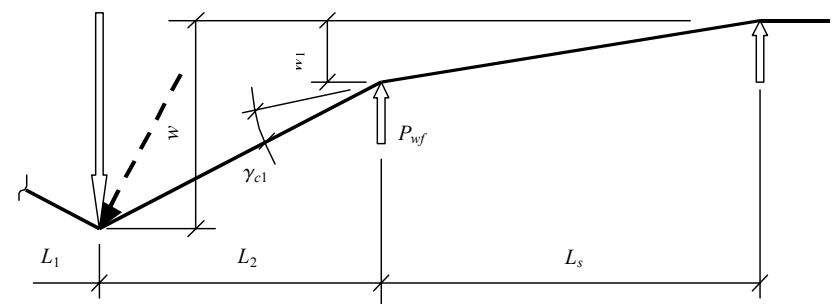

Figure 6 - Deflection and Forces in Web Frames

The deflection at the outermost distorted web is:

$w_{n}=\frac{L_{s}}{L_{i}+n L_{s}}\left\{w-\gamma_{c 2}\left[n L_{i}+\frac{1}{2}(n-1) n L_{s}\right]\right\}$

where:

$n$ - number of deformed web frames on $L_{i}$ side

$L_{s}$ - web frame spacing $(\mathrm{m})$

The deflection at other deformed web frames is:

$w_{j}=(n-j+1) w_{n}+\frac{1}{2}(n-j)(n-j+1) \gamma_{c 2} L_{s}$

where $j$ is the number of webs counted from the striking point. The elongation in adjacent webs is:

$e_{j}=\sqrt{\left(w_{j}-w_{j+1}\right)^{2}+L_{s}^{2}}-L_{s}$ and the elongation in the struck web is:

$e_{0 i}=\sqrt{\left(w-w_{1}\right)^{2}+L_{i}^{2}}-L_{i}$

With these elongation and deformation results, the rupture criteria given in Equations (13) and (14) are applied to all deformed webs. The total elongation on the $L_{i}$ side is:

$e_{t i}=e_{0 i}+\sum_{j=1}^{n} e_{j i}$

and the energy absorbed in membrane tension and web deformation is:

$E_{i}=T_{i} e_{t i}+P_{w f} \sum_{j=1}^{n} w_{j i}$

For right angle collisions, $T_{i}$ always equals $T_{m}$ as calculated in Equation (10). In oblique angle collisions, $T_{i}$ equals $T_{m}$ if $L_{i}$ is on the side behind the strike. Based on experimental data, Rosenblatt (1975) suggests using $1 / 2 T_{m}$ ahead of the strike and this is used in SIMCOL 2.1.

For double hull ships, if the web frames are distorted because of bending, shearing and buckling of supporting struts, the deformed web frames push the inner skin into membrane tension as shown in Figure 3 , and the right angle collision mechanism is applied to the inner hull. Inner skin integrity is checked using Equations (13) and (14), and the energy absorbed in inner skin membrane tension is calculated using Equation (10).

In the simulation, the energy absorbed in membrane tension and web deformation during the time step is:

$\Delta K E_{n}=\left(E_{1, n+1}+E_{2, n+1}\right)-\left(E_{1 n}+E_{2, n}\right)$

Considering the friction force, $F_{f}$, shown in Figure 5, and assuming the dynamic coefficient of friction is a constant value of 0.15 , the reacting forces and moments are:

$\Delta K E_{n}=N_{n}\left(w_{n+1}-w_{n}\right)+F_{f n}\left|l_{n+1}-l_{n}\right|=N\left[\left(w_{n+1}-w_{n}\right)+0.15\left|l_{n+1}-l_{n}\right|\right]$

$F_{\eta n}=N_{n}=\frac{\left(E_{1, n+1}+E_{2, n+1}\right)-\left(E_{1 n}+E_{2, n}\right)}{\left(w_{n+1}-w_{n}\right)+0.15\left|l_{n+1}-l_{n}\right|}$

$F_{\xi n}=F_{f} \frac{\left(l_{n+1}-l_{n}\right)}{\left|l_{n+1}-l_{n}\right|}=0.15 F_{\eta n} \frac{\left(l_{n+1}-l_{n}\right)}{\left|l_{n+1}-l_{n}\right|}$

$M_{n}=-F_{\xi n} d_{n}+F_{\eta n} l_{n}$

In addition to the friction force, another longitudinal force, $F_{R}$, the force to propagate the yielding zone, is considered, as shown in Figure 5. McDermott (1974) provides an expression for this force:

$F_{R}=\frac{\sigma_{y} d^{\prime}}{R}\left[d^{\prime} t_{w}\left(1-\frac{\sigma_{y} R}{d^{\prime} E}\right)^{2}+t_{f}\left(b-t_{w}\right)\left(\frac{d^{\prime}-0.5 t_{f}}{d^{\prime}}-\frac{\sigma_{y} R}{d^{\prime} E}\right)\right]$

where: 
$d^{\prime}$ - depth of side shell longitudinal stiffeners

$R$ - radius of the striking bow

$t_{w}$ - thickness of side shell stiffener webs

$t_{f}$ - thickness of side shell stiffener flanges

$b$ - width of side shell stiffener flanges

$E$ - modulus of elasticity

The full implementation of Equation (26) requires structural details that are not appropriate for a simplified analysis. In this study, based on a sampling of typical side shell scantlings, a simplified calculation is used where $c_{F} \cdot c_{A}$ is assumed to have a constant value of 0.025 :

$c_{F}=\frac{F_{R}}{\sigma_{y} A_{\text {stiff }}}$

$c_{A}=\frac{A_{\text {stiff }}}{A_{\text {total }}}$

$F_{R}=c_{F} c_{A} \sigma_{y} t B$

and:

$c_{F}$ - force coefficient;

$c_{A}$ - ratio of sectional areas;

$A_{\text {stiff }}$ - sectional area of stiffeners; and

$A_{\text {total }^{-}}$total sectional area of stiffeners and their attached plate.

Since $F_{R}$ also effects membrane tension energy, Equation (25) becomes:

$\Delta K E_{n}=F_{\eta n}\left[\left(w_{n+1}-w_{n}\right)+0.15\left|l_{n+1}-l_{n}\right|\right]+F_{R}\left(l_{n+1}-l_{n}\right)$

$F_{\eta n}=\frac{\left(E_{1, n+1}+E_{2, n+1}\right)-\left(E_{1 n}+E_{2, n}\right)-F_{R}\left(l_{n+1}-l_{n}\right)}{\left(w_{n+1}-w_{n}\right)+0.15\left|l_{n+1}-l_{n}\right|}$

$F_{\xi n}=\left(F_{R}+0.15 F_{\eta n}\right) \frac{\left(l_{n+1}-l_{n}\right)}{\left|l_{n+1}-l_{n}\right|}$

$M_{n}=-F_{\xi n} d_{n}+F_{\eta n} l_{n}$

The Internal Sub-Model determines absorbed energy and forces from the crushing and tearing of decks, bottoms and stringers (horizontal structures) in a simplified manner using the Minorsky (1959) correlation as modified by Reardon and Sprung (1996).

V.U. Minorsky conducted the first and best known of the empirical collision studies based on actual data. His method relates the energy dissipated in a collision event to the volume of damaged structure. Actual collisions in which ship speeds, collision angle, and extents of damage are known were used to empirically determine a linear constant. This constant relates damage volume to energy dissipation. In the original analysis the collision is assumed to be totally inelastic, and motion is limited to a single degree of freedom. Under these assumptions, a closed form solution for damaged volume can be obtained. With additional degrees of freedom, a time-stepped solution must be used.

Step 2 in the collision simulation process calculates damaged area and volume in the struck ship given the relative motion of the two ships in a time step calculated in Step 1 by the External Sub-Model. Figure 7 illustrates the geometry of the sweeping segment method used for this calculation in SIMCOL Version 2.1.

The intrusion portion of the bow is described with five nodes, as shown in Figure 7. The shaded area in Figure 7 shows the damaged area of decks and/or bottoms during the time step. Coordinates of the five nodes in the $\xi-\eta$ system at each time step are derived from the penetration and location of the impact, the collision angle, $\phi$, and the half entrance angle, $\alpha$, of the striking bow.

The damaged plating thickness $t$ is the sum thickness of deck and/or bottom structures that are within the upper and lower extents of the striking bow. Given the damaged material volume, the Minorsky force is calculated based on the following assumptions:

- The resistant force acting on each out-sweeping segment is in the opposite direction of the average movement of the segment. The force exerted on the struck ship is in the direction of this average movement.

- The work of the resistant force is done over the distance of this average movement.

- The total force on each segment acts through the geometric center of the sweeping area.

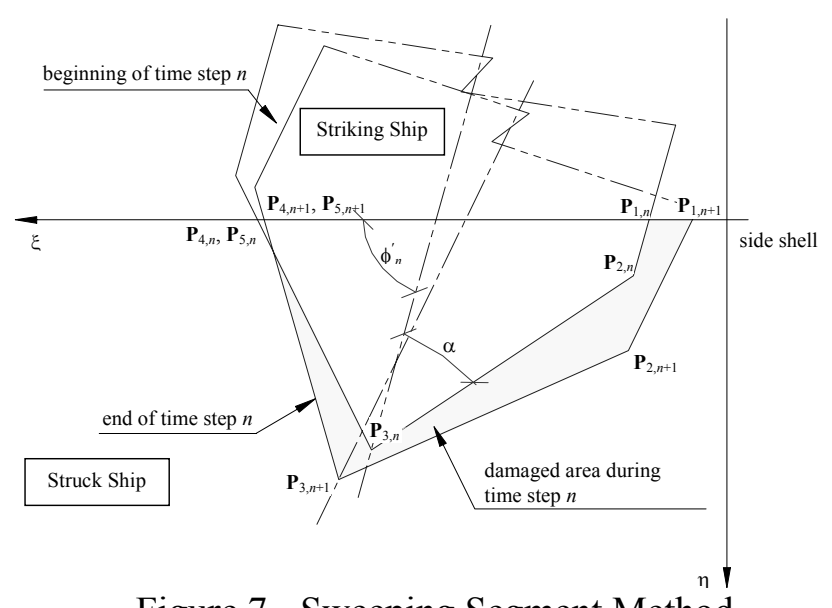

Figure 7 - Sweeping Segment Method

The energy absorbed is then:

$$
\Delta K E_{1, n}=47.1 \times 10^{6} R_{T 1, n}=47.1 \times 10^{6} A_{1, n} t
$$

where: 
$\triangle K E$ - kinetic energy absorbed by decks, bottoms and stringers $(\mathrm{J})$

$R_{T}$ - damaged volume of structural members $\left(\mathrm{m}^{3}\right)$

$A$ - damaged area of the decks or bottoms swept by each bow segment $\left(\mathrm{m}^{2}\right)$

$t$ - total thickness of impacted decks or bottoms (m)

Forces and moments acting on other segments are calculated similarly. The total exerted force, $\mathbf{F}_{n}$, is the sum of the forces and moments on each segment:

$\mathbf{F}_{n}=\sum_{i=1}^{4}\left\{F_{\xi i, n}, F_{\eta i, n}, M_{i, n}\right\}$

These forces are added to the side shell, bulkhead and web forces. Internal forces and moments are calculated for the struck ship in the local coordinate system, i.e. the $\xi-\eta$ system, and converted to the global system. The forces and moments on the striking ship have the same magnitude and the opposite direction of those acting on the struck ship.

\subsection{SIMCOL Input Data}

SIMCOL requires two types of input data:

- Data describing the struck ship

- Data describing the collision scenario and striking ship

The struck ship data includes: struck ship type (single hull or double hull); principal characteristics (LBP, B, D, T, $\Delta$ ); transverse web spacing; description of primary subdivision (number and location of transverse bulkheads, number and location of longitudinal bulkheads including the side shell); smeared plate thickness of side shell, longitudinal bulkheads, decks, bottom; material grades of side shell, longitudinal bulkheads, decks, bottom; number, width, location, smeared thickness, and material of side stringers; side shell supports including decks, bottom, and struts; web material, thickness, stiffener spacing, supported length; and strut material, area, radius of gyration, and critical length.

The scenario data includes: striking ship principal characteristics; striking ship bow half-entrance angle (HEA), speed of the struck ship; speed of the striking ship; impact point location; and collision angle.

\section{Collision Scenarios}

The collision scenario is described using random variables with varying degrees of dependency. Two primary data sources are used to determine the probabilities and probability density functions necessary to define these random variables:
- Lloyd's Worldwide Ship data (1993)

Sandia considers collision data from 4 sources:

1. Lloyd's Casualty Data for 1973 to 1993 contains 30,000 incident reports of which 1947 were ship to ship collision events, 702 of which occurred in ports. This data was used primarily to estimate the probability and geographical location of collisions and fires that could harm nuclear flasks. It did not include specific scenario and technical data. It is not directly applicable to collision scenarios.

2. ORI Analysis (1980) - includes a summary of data from cargo vessel accidents in 1974 and 1975 for 78000 transits of ships over 5000 gross tons. Most of this data is from the USCG Commercial Vessel Casualty File. It includes 216 collisions for ships in US waters or US ships in international waters. 8 collisions of tankers and cargo ships and other tanker accidents from the ECO World Tanker Accident file are also included. This totals 1122 cargo ship accidents. 115 are struck cargo ship collisions with more than 90 percent of these in inland and coastal waters. The study addresses the probability of various accident types.

3. ORI Analysis (1981) - This study uses the same data as the ORI (1980) Study. It includes the probability of striking ship displacement, speed, collision angle and collision location for struck cargo ship collisions.

4. Engineering Computer Optecnomics, Inc (ECO) World Fleet Data.

Applicable subsets of this data are described here. In this paper, pdfs generated from this data are used to develop 10000 collision cases that are applied to four struck tanker designs, for a total of 40000 SIMCOL runs. SIMCOL calculates damage penetration, damage length, oil outflow and absorbed energy for each of these runs.

- Sandia Report (1998) 


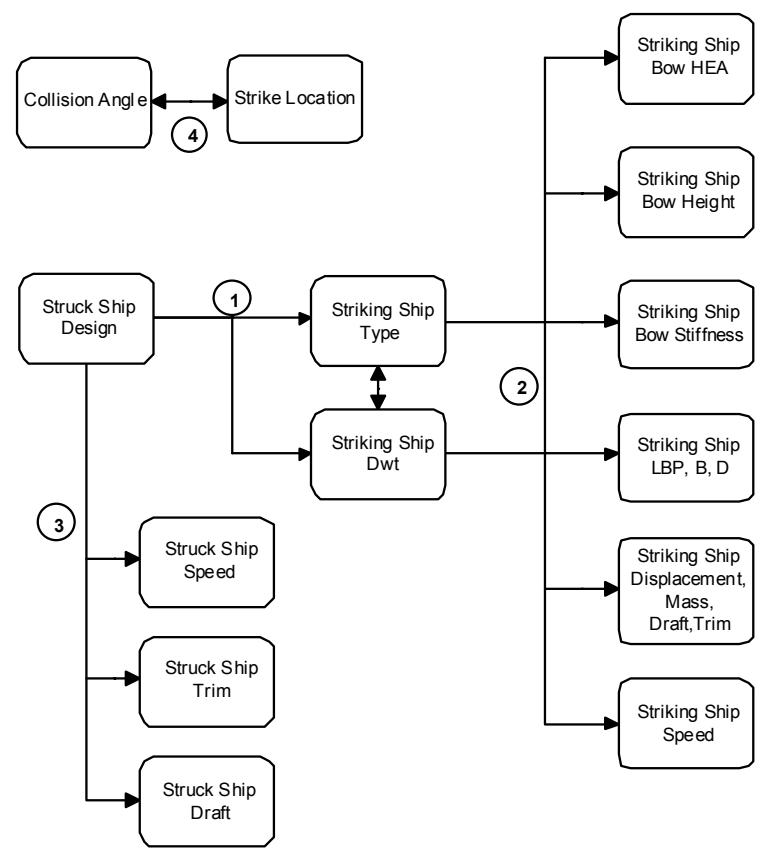

Figure 8 - Collision Event Variables

\subsection{Collision Event Variables}

Collision event variables are not expected to be independent, but their interdependence is difficult to quantify because of limited collision data. Figure 8 provides a framework for defining the relationship of scenario variables. Available data is incomplete for quantifying this relationship. Strike location must often be inferred from the damage description because reliable records of the precise location are not available. Ship headings and speeds prior to the collision are often included in accident reports, but collision angle and ship speed at the moment of collision are frequently not included or only estimated and described imprecisely.

\subsection{Striking Ship Type and Displacement}

Figure 9 provides probabilities of the struck ship encountering specific ship types. These probabilities are based on the fraction of each ship type in the worldwide ship population in 1993. Each of the general types includes a number of more specific types:

- Tankers - includes crude and product tankers, ore/oil carriers, LPG tankers, chemical tankers, LNG tankers, and oil/bulk/ore carriers

- Bulk carriers - includes dry bulkers, ore carriers, fish carriers, coal carriers, bulk/timber carriers, cement carriers and wood chip carriers

- Cargo vessels (Break Bulk / Freighters) includes general freighters and refrigerated freighters

- Passenger - includes passenger and combo passenger/cargo ships
- Containerships - includes containerships, car carriers, container/RO-ROs, ROROs, bulk/car carriers, and bulk/containerships

It is likely that particular ships are more likely to meet ships of the same type since they travel the same routes, but this relationship could not be established with available data. Additional collision data must be obtained to establish this relationship.

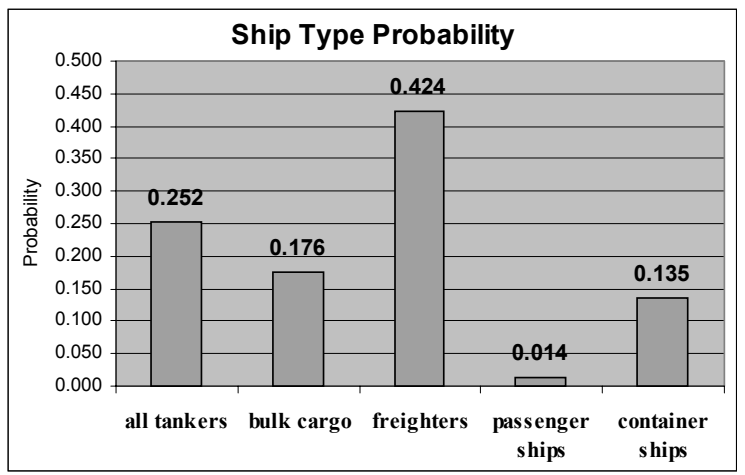

Figure 9 - Striking Ship Type Probability

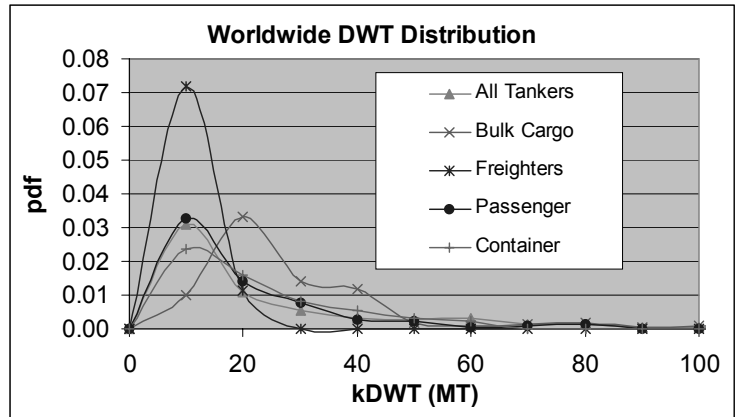

Figure 10 - Striking Ship Displacement, Worldwide

Table 2 - Striking Ship Type and Displacement

\begin{tabular}{|l|l|l|l|l|l|}
\hline Ship Type & $\begin{array}{l}\text { Probability } \\
\text { of Encounter }\end{array}$ & $\begin{array}{c}\text { Weibull } \\
\boldsymbol{\alpha}\end{array}$ & $\begin{array}{c}\text { Weibull } \\
\boldsymbol{\beta}\end{array}$ & $\begin{array}{c}\text { Mean } \\
(\mathbf{k M T})\end{array}$ & $\begin{array}{c}\boldsymbol{\sigma} \\
(\mathbf{k M T})\end{array}$ \\
\hline Tanker & 0.252 & 0.84 & 11.2 & 12.277 & 14.688 \\
\hline Bulk carrier & 0.176 & 1.20 & 21.0 & 19.754 & 16.532 \\
\hline Cargo & 0.424 & 2.00 & 11.0 & 9.748 & 5.096 \\
\hline Passenger & 0.014 & 0.92 & 12.0 & 12.479 & 13.579 \\
\hline Container & 0.135 & 0.67 & 15.0 & 19.836 & 30.52 \\
\hline
\end{tabular}

Figure 10 shows the worldwide distributions of displacement for these ship types. The distributions are significantly different and must be applied individually to each ship type. Weibull density function $\alpha$ and $\beta$ values for each distribution are provided in Table 2 .

Collision speed is the striking ship speed at the moment of collision. It is not necessarily related to service speed. It depends primarily on actions taken just prior to collision. Collision speed data is collected from actual collision events. Figure 11 is a plot of data derived from the Sandia Report (1998) and limited USCG tanker-collision data (1990). An approximate Weibull distribution $(\alpha=2.2, \beta=6.5)$ is fit to this data. The mean of this distribution is substantially less than service speed(s), and indicates 
significant adjustment in speed prior to the actual collision event.

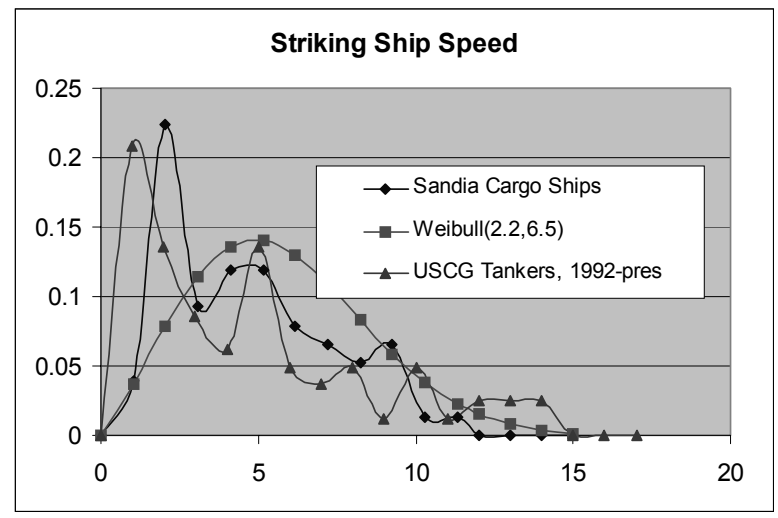

Figure 11 - Striking Ship Speed

\subsection{Striking Ship Principal Characteristics}

In this section, data and regression curves are presented for deriving striking ship half-entrance angle, length, beam, draft, and bow height from striking ship type and displacement.

Bow half-entrance angle is not a standard ship principal characteristic. A limited number of bow drawings were reviewed in the Sandia Study. Table 3 presents the results of this analysis. The trends in this data are difficult to explain and the data is insufficient to derive pdfs. Table 4 provides single values derived from Table 3 for each type of ship. These values are used in this study.

Lloyd's worldwide data (1993) is used to specify the remaining principal characteristics as a function of ship type and displacement. Typical principal characteristic data is plotted in Figure 12. This data is fit to a power function of the form: $\mathrm{y}=\mathrm{Cx}^{\mathrm{a}}$ where $\mathrm{x}$ is displacement in tonne. Table 4 provides values for coefficients and powers used in these equations.

Table 3 - Bow Half Entrance Angle (all ships) [12]

\begin{tabular}{|c|c|c|c|c|}
\hline Displacement & \multicolumn{4}{|c|}{ Bow Half Entrance Angle, (Degrees) } \\
\hline (tonne) & Tanker & Cargo & Container & Passenger \\
\hline $0-10160$ & 28 & 29 & 17 & 17 \\
\hline $10160-20320$ & 30 & 20 & 17 & 17 \\
\hline $20320-30480$ & 30 & 20 & 17 & 17 \\
\hline $30480-40640$ & 38 & 20 & 17 & 17 \\
\hline $40640-50800$ & 38 & 20 & 17 & 17 \\
\hline $50800-60960$ & 38 & 20 & 17 & 17 \\
\hline $60960-71120$ & 38 & 20 & 17 & 17 \\
\hline $71120-81280$ & 38 & 20 & 17 & 17 \\
\hline $81280-$ above & 38 & 20 & 17 & 17 \\
\hline
\end{tabular}

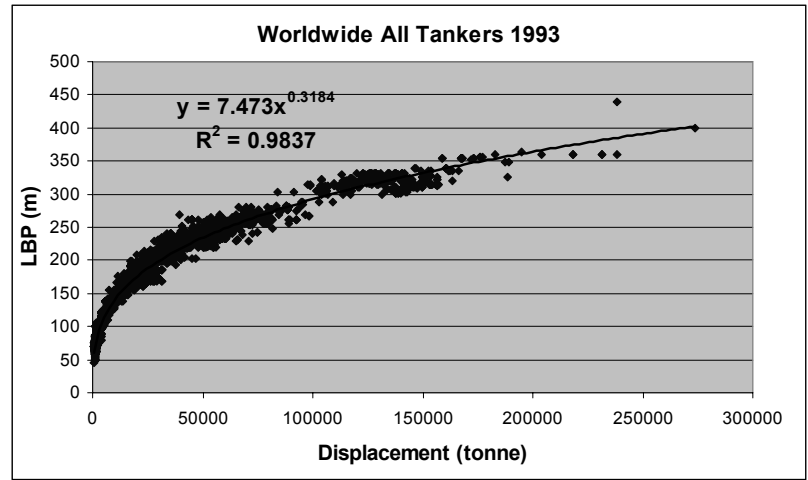

Figure 12 - Tankers Length vs. Displacement

Table 4 - Striking Ship Characteristics $\left(\mathrm{y}=\mathrm{Cx}^{\mathrm{a}}\right.$ where $\mathrm{x}$ is displacement in tonne)

\begin{tabular}{|c|c|c|c|c|c|c|c|c|c|}
\hline & \multicolumn{2}{|c|}{} & \multicolumn{2}{|c|}{$\begin{array}{l}\text { Beam } \\
\text { (m) }\end{array}$} & \multicolumn{2}{|c|}{ Draft (m) } & \multicolumn{2}{|c|}{$\begin{array}{c}\text { Bow Height } \\
\text { (m) }\end{array}$} & $\begin{array}{c}\text { H } \\
\text { E } \\
\mathbf{A}\end{array}$ \\
\hline & $\mathrm{C}$ & $\mathrm{a}$ & $\mathrm{C}$ & $\mathrm{a}$ & $\mathrm{C}$ & $\mathrm{a}$ & $\mathrm{C}$ & $\mathrm{a}$ & \\
\hline Tanker & 7.47 & .318 & 1.15 & .321 & .574 & .297 & .671 & .320 & 38 \\
\hline $\begin{array}{c}\text { Bulk } \\
\text { carrier }\end{array}$ & 6.6 & .332 & .96 & .336 & .547 & .303 & 1.31 & .261 & 20 \\
\hline Freighter & 6.93 & .325 & 1.72 & .273 & .474 & .320 & .741 & .321 & 20 \\
\hline $\begin{array}{c}\text { Passenger } \\
\text { ship }\end{array}$ & 8.22 & .299 & 1.97 & .256 & .889 & .210 & 1.13 & .258 & 17 \\
\hline $\begin{array}{c}\text { Container } \\
\text { ship }\end{array}$ & 5.49 & .353 & 1.96 & .265 & .596 & .284 & .746 & .317 & 17 \\
\hline
\end{tabular}

\subsection{Struck Ship Variables}

Figure 13 is a plot of struck ship speed derived from the USCG tanker collision data. The struck ship collision speed distribution is also very different from service speed. Struck ships are frequently moored or at anchor as is indicated by the significant pdf value at zero speed. An exponential distribution $(\alpha=0.584)$ is fit to this data. Full load displacement and draft with zero trim are assumed for the struck ship in this paper.

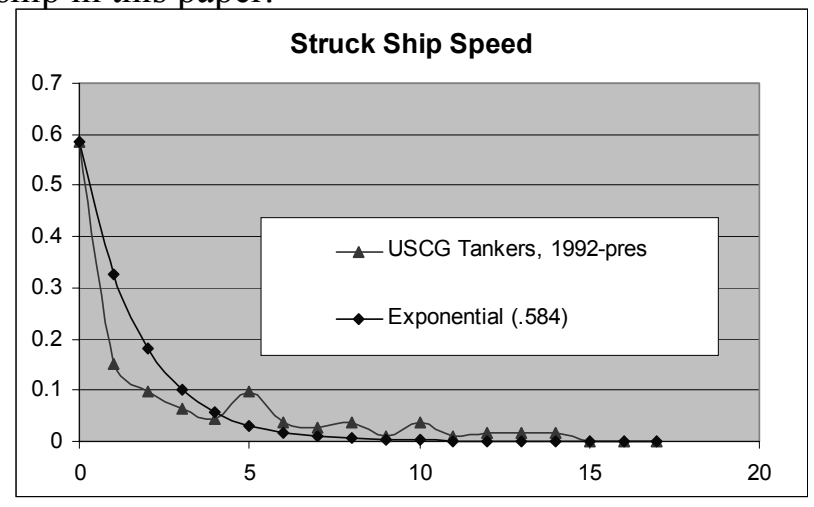

Figure 13 - Struck Ship Speed

\subsection{Remaining Collision Scenario Variables}

An approximate Normal distribution $(\mu=90$ degrees, $\sigma=28.97$ degrees) is fit to collision angle data derived from the Sandia Report, and is used to select collision angle in the Monte Carlo simulation. 
At more oblique angles, there is a higher probability of ships passing each other or only striking a glancing blow. These cases are frequently not reported.

The current IMO pdf for longitudinal strike location specifies a constant value over the entire length of the stuck ship, IMO (1995). The constant pdf was chosen for convenience and because of the limited available data. Figure 14 shows a bar chart of the actual data used to develop the IMO pdf, IMO (1989), and data gathered for cargo ships in the Sandia Study. This data does not indicate a constant pdf. The IMO data is from 56 of 200 significant tanker-collision events for which the strike location is known. The Sandia data indicates a somewhat higher probability of midship and forward strike compared to the IMO data. The IMO tanker probabilities are used in this study.

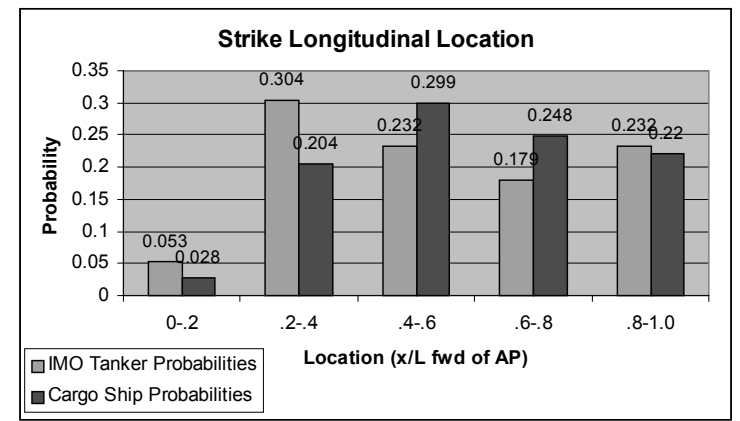

Figure 14 - Longitudinal Damage Location Probabilities

\section{Sensitivity Analysis}

\subsection{Struck Ships}

Four struck ships are used in the sensitivity analysis. The ships include two 150k dwt oil tankers, one single hull and one double hull, and two $45 \mathrm{k} \mathrm{dwt}$ oil tankers, one single hull and one double hull. SIMCOL input data for these ships are provided in Tables 5 and 6. Collision scenario pdfs specified in Section 3 are used to develop 10000 collision cases that are applied to each of the four ships using SIMCOL. SIMCOL calculates damage penetration, damage length and absorbed energy for each of these cases.

Table 5 - Struck Ship Principal Characteristics

\begin{tabular}{|l|c|c|c|c|}
\hline & DH150 & SH150 & DH45 & SH45 \\
\hline Displacement, MT & 151861 & 152395 & 47448 & 47547 \\
\hline Length, m & 261.0 & 266.3 & 190.5 & 201.2 \\
\hline Breadth, m & 50.0 & 50 & 29.26 & 27.4 \\
\hline Depth, m & 25.1 & 25.1 & 15.24 & 14.3 \\
\hline Draft, m & 16.76 & 16.76 & 10.58 & 10.6 \\
\hline Double bottom height, m & 3.34 & NA & 2.1 & NA \\
\hline Double hull width, m & 3.34 & NA & 2.438 & NA \\
\hline
\end{tabular}

Table 6 - Stuck Ship Structural Characteristics

\begin{tabular}{|l|c|c|c|c|}
\hline & DH150 & SH150 & DH45 & SH45 \\
\hline Web frame spacing,mm & 5.2 & 5.2 & 3.505 & 3.89 \\
\hline Smeared deck thickness, mm & 29.4 & 28.2 & 27.6 & 30.5 \\
\hline $\begin{array}{l}\text { Smeared inner bottom thickness, } \\
\text { mm }\end{array}$ & 37.1 & NA & 27.8 & NA \\
\hline
\end{tabular}

\begin{tabular}{|l|c|c|c|c|}
\hline Smeared bottom thickness, $\mathrm{mm}$ & 36.6 & 44.2 & 34 & 38.5 \\
\hline Smeared stringer thickness, $\mathrm{mm}$ & 14.9 & NA & NA & NA \\
\hline Smeared side shell thickness, $\mathrm{mm}$ & 26.7 & 27.8 & 24.5 & 23.6 \\
\hline Smeared inner side thickness, $\mathrm{mm}$ & 28.1 & NA & 20.1 & NA \\
\hline Smeared long bhd thickness, $\mathrm{mm}$ & 25.1 & 24.5 & 20 & 33.4 \\
\hline Smeared upper web thickness & 12.5 & 12.5 & 12.7 & 19 \\
\hline Smeared lower web thickness & 14.5 & 16 & 12.7 & 19 \\
\hline
\end{tabular}

\subsection{Results and Discussion}

Figures 15 and 16 are the resulting probability density functions for damage penetration and damage length. Table 7 lists mean values for scenario variables, damage penetration, and damage length. The damage pdfs for the four struck ships are quite similar. Unlike the IMO standard pdfs, penetration in these pdfs is not normalized with breadth. The larger struck ships must absorb more energy due to their higher inertia, but structural scantlings are also larger so damage penetrations and lengths for the $150 \mathrm{k}$ dwt ships are similar to the $45 \mathrm{k}$ dwt ships. Comparing the mean values in Table 7 , on the average, the single hull ships do have larger penetrations and damage lengths than the double hull ships, and the larger ships have larger penetrations and damage lengths than the smaller ships.

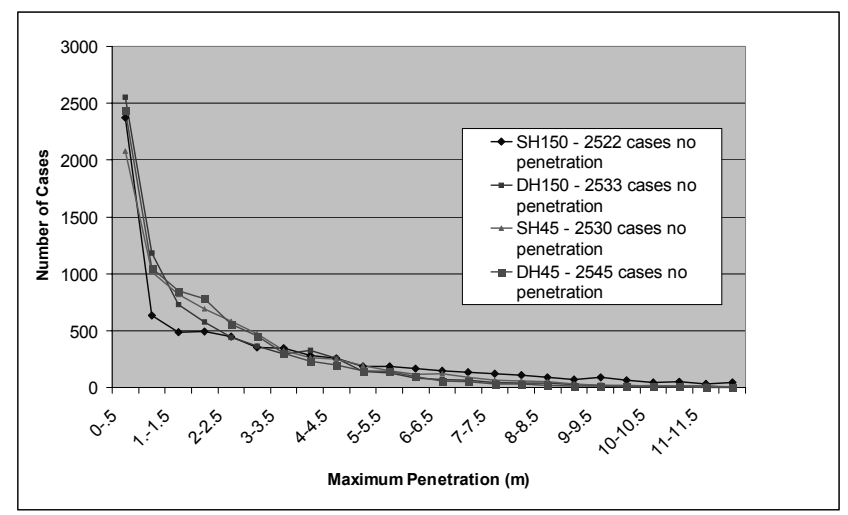

Figure 15 - Damage Penetration pdf

In order to assess the sensitivity of damage penetration and length to the collision scenario variables, a second order polynomial response surface is fit to the 10000 cases of SIMCOL results for each ship. Figures 17 to 22 provide the results of this analysis. In each of the figures, the other collision scenario variables are assigned the mean values listed in Table 7. 


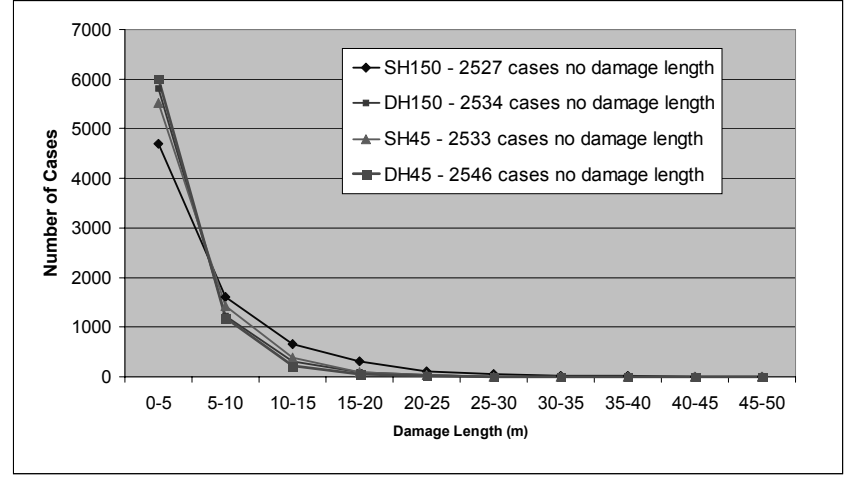

Figure 16 - Damage length pdf

Table 7 - Mean Scenario and Damage Values

\begin{tabular}{|l|r|r|r|r|r|}
\hline & All & DH150 & SH150 & DH45 & SH45 \\
\hline Mean Struck Ship Velocity (knots) & 2.49 & & & & \\
\hline Mean Striking Ship Velocity (knots) & 4.27 & & & & \\
\hline Mean Strike Location (x/L) & 0.47 & & & & \\
\hline Mean Collision Angle & 90.00 & & & & \\
\hline Mean Striking Ship Displacement (tonne) & 13660.00 & & & & \\
\hline Mean Damage Penetration (meters) & & 1.385 & 2.28 & 1.281 & 1.571 \\
\hline Mean Damage Length (meters) & & 2.523 & 3.87 & 2.291 & 2.809 \\
\hline
\end{tabular}

Figure 17 shows a very significant increase in damage penetration as a function of striking ship displacement with diminishing increases above 40k tonne. The variation with strike location (Figure 18) is much less with smaller penetrations for strikes away from midships where more striking energy is converted to struck ship yaw.

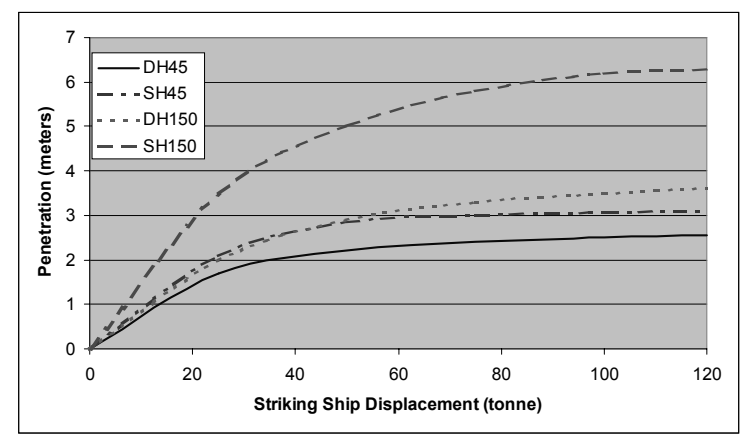

Figure 17 - Penetration vs. Striking Ship Displacement

Figure 19 shows penetration is very sensitive to striking ship speed over the full range of speeds considered. Figure 20 shows that penetration is also very sensitive to collision angle with maximum penetration occurring at 80 to 85 degrees (from the bow) where kinetic energy from both striking and struck ships combine to maximize penetration. Collision angles below approximately 25 degrees and above 150 degrees result in glancing blows that do not penetrate. Figure 21 shows damage lengths are largest for collision angles of approximately 75 degrees. Figure 22 shows penetration is less sensitive to struck ship speed.

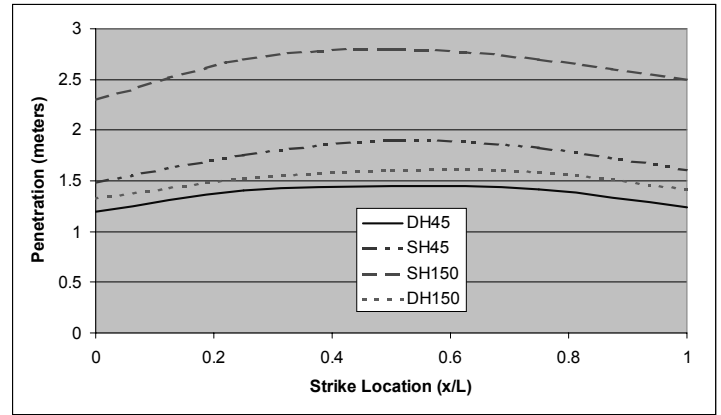

Figure 18 - Penetration versus Strike Location

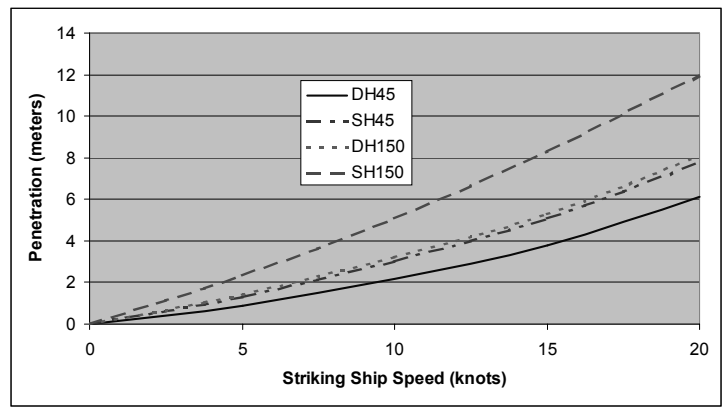

Figure 19 - Penetration versus Striking Ship Speed

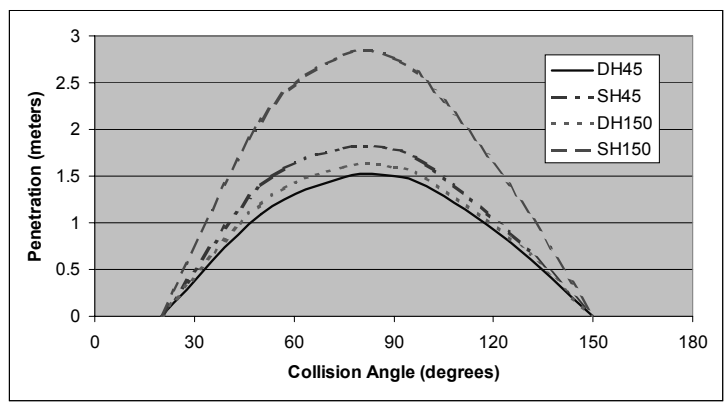

Figure 20 - Penetration versus Collision Angle

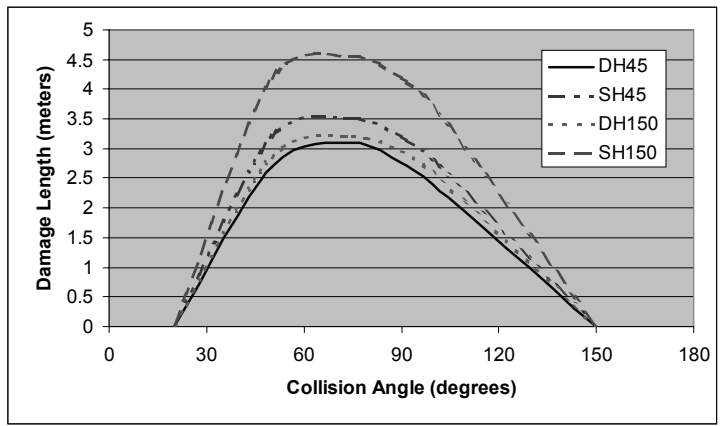

Figure 21 - Damage Length versus Collision Angle

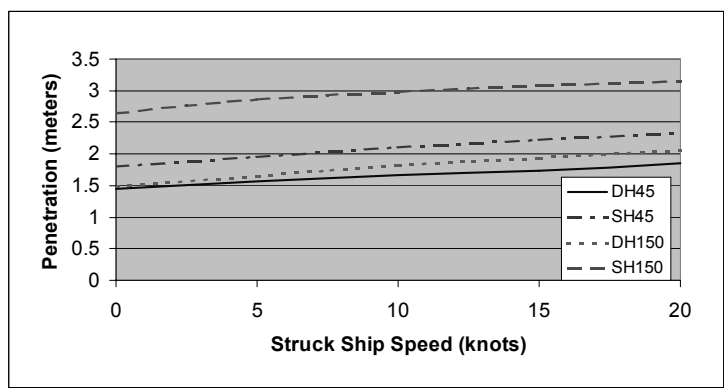

Figure 22 - Penetration versus Struck Ship Speed 


\section{Absorbed Energy}

A potential simplification for the collision scenario definition requires that the external ship dynamics problem be solved uncoupled from the internal deformation problem. This would allow multiple collision scenario random variable definitions to be replaced by pdfs for transverse and longitudinal absorbed energy only. This section examines the validity of this simplification.

\subsection{Absorbed Energy Calculation}

Zhang and Pedersen (1998) derive expressions for absorbed energy uncoupled from internal mechanics. Collision absorbed energy in the $\xi$ (transverse) direction and $\eta$ (longitudinal) direction are:

$$
\begin{aligned}
& E_{\xi}=\int_{0}^{\xi_{\max }} F_{\xi} d \xi=\frac{1}{2} \frac{1}{D_{\xi}+\mu D_{\eta}} \dot{\xi}(0)^{2} \\
& E_{\eta}=\int_{0}^{\eta_{\max }} F_{\eta} d \eta=\frac{1}{2} \frac{1}{\frac{1}{\mu} K_{\xi}+K_{\eta}} \dot{\eta}(0)^{2} \\
& E_{\text {total }}=E_{\xi}+E_{\eta}
\end{aligned}
$$

where the coefficients $\mathrm{D}_{\xi}, \mathrm{D}_{\eta}, \mathrm{K}_{\xi}, \mathrm{K}_{\eta}$ are algebraic expressions that are a function of the ship masses, strike location, collision angle, and added mass coefficients. Assumed added mass coefficients are 0.05 in surge, 0.85 in sway and 0.21 in yaw. $\eta \operatorname{dot}(0)$ and $\xi \operatorname{dot}(0)$ are the relative longitudinal and transverse velocities between the two ships just prior to impact. Equation (30) assumes that the two ships stick together on impact. Whether the two ships slide or stick is determined by the ratio of transverse to longitudinal force impulses at impact. If this ratio exceeds the coefficient of static friction, it is assumed that the two ships slide. The impulse ratio at impact is assumed to be constant for the entire process.

Absorbed energy in SIMCOL is calculated by multiplying transverse force by transverse displacement and longitudinal force by longitudinal displacement for each time step, and then summing for all time steps until the end of the collision event. The relationship between longitudinal and transverse forces is very dependent on the internal deformation of the structure and their relationship varies from time step to time step as the struck ship s penetrated.

\subsection{Absorbed Energy Results and Discussion}

Figures 23-25 compare absorbed energy calculated using the Zhang method to energy calculated using SIMCOL. Total absorbed energy shown in Figure 23 is very similar in the two cases, particularly considering the significant difference in the two methods.

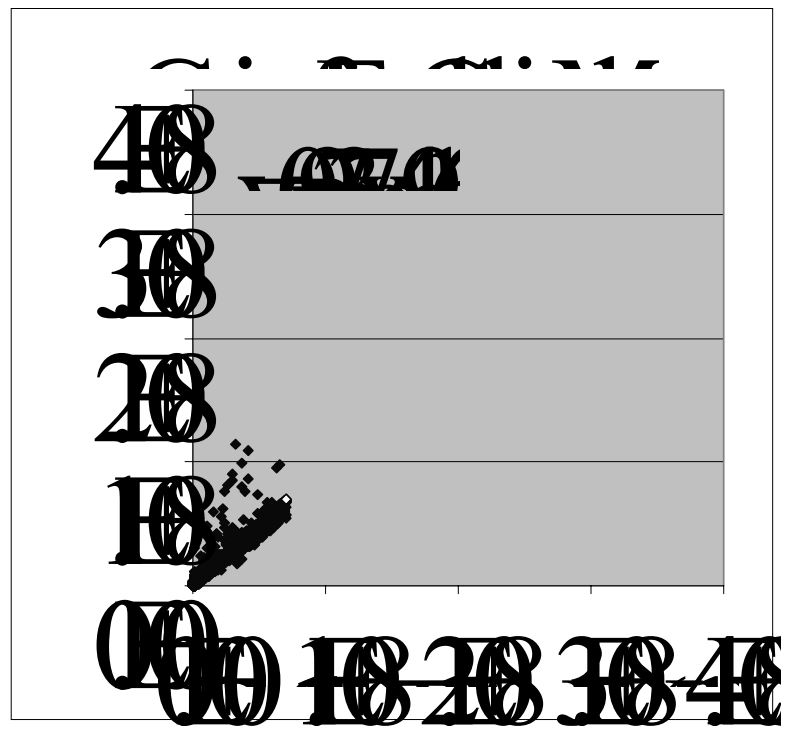

Figure 23 - Total Absorbed Energy

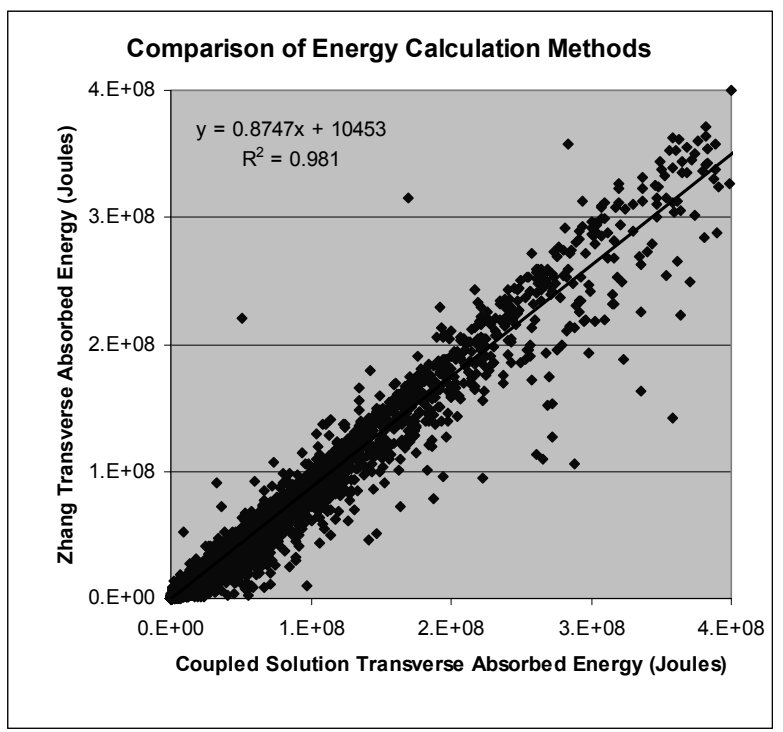

Figure 24 - Transverse Absorbed Energy

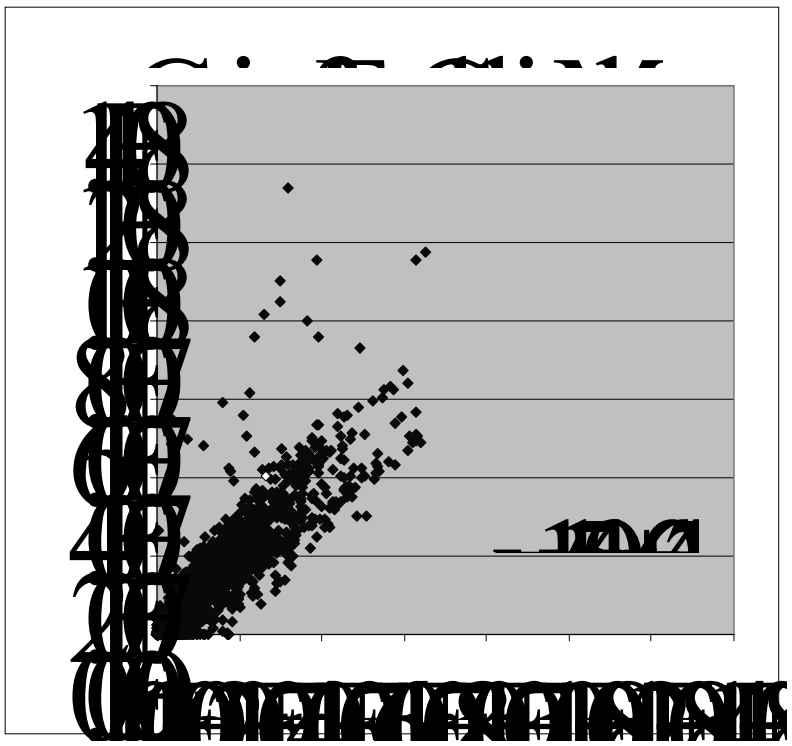

Figure 25 - Longitudinal Absorbed Energy 
The longitudinal and transverse components show a larger difference, particularly in the longitudinal direction. This may result from differences in structural resistance in the transverse and longitudinal directions, which in SIMCOL varies during the collision process. The difference in longitudinal absorbed energy is potentially significant because once the structure is penetrated, longitudinal damage extent determines the number of compartments that are opened to the sea. This has a significant effect on damage stability and oil outflow.

\section{Conclusions and Recommendations}

An accurate definition of collision scenario random variables is essential for predicting collision damage penetration and length. Probabilistic damage extents are very sensitive to striking ship displacement, striking ship speed and collision angle. A significant effort is warranted to insure that pdfs for these random variables are correct. Damage extents are less sensitive to struck ship speed and strike location.

When estimating damage stability and oil outflow, damage length is a very important factor. Using uncoupled methods to predict absorbed longitudinal energy may not provide sufficient accuracy for this calculation.

Normalization of damage extents using struck ship principal characteristics $(\mathrm{L}, \mathrm{B}, \mathrm{D})$ as in the standard IMO pdfs may not be a reasonable approach over the full range of collision scenarios. This requires further investigation.

Future work will investigate the sensitivity of probabilistic damage extents to struck ship structural scantlings and will consider striking ship bow deformation.

\section{References}

Brown, A.J. and M. Amrozowicz, 1996. "Tanker Environmental Risk - Putting the Pieces Together", SNAME/SNAJ International Conference on Designs and Methodologies for Collision and Grounding Protection of Ships.

Brown, A.J. et al., 2000. "Structural Design and Response in Collision and Grounding", presented at the SNAME Annual Meeting.

Chen, D., 2000. "Simplified Collision Model (SIMCOL)", Dept. of Ocean Engineering, Virginia Tech, Master of Science Thesis.

Crake, K., 1995. "Probabilistic Evaluations of Tanker Ship Damage in Grounding Events", Naval Engineer Thesis, MIT.
Hutchison, B.L., 1986. "Barge Collisions, Rammings and Groundings - an Engineering Assessment of the Potential for Damage to Radioactive Material Transport Casks", Report No. SAND85-7165 TTC-05212.

IMO, 1989. "Comparative Study on Oil Tanker Design," IMO paper MEPC 32/7/15, Annex 5, Distribution of Actual Penetrations and Damage Locations Along Ship's Length for Collisions and Groundings.

IMO, 1995. "Interim Guidelines for Approval of Alternative Methods of Design and Construction of Oil Tankers under Regulation 13F(5) of Annex I of MARPOL 73/78", Resolution MEPC.66 (37).

Lloyds Worldwide Ship data, 1993. provided by MARAD.

Lutzen, M., Simonsen, B.C., and Pedersen, P.T., 2000. "Rapid Prediction of Damage to Struck and Striking Vessels in a Collision Event", SSC 2000.

Lutzen, M. and Clausen, H.B., 2001, "Collision Energy Distribution", draft HARDER Paper.

McDermott, J.F., et al, 1974. "Tanker Structural Analysis for Minor Collisions", SNAME Transactions, Vol. 82, pp. 382-414.

Minorsky, V. V., 1959. "An Analysis of Ship Collisions with Reference to Proteciton of Nuclear Power Plants," Journal of Ship Research.

ORI, 1980. Hazardous Environment Experienced by Radioactive Material Packages Transported by Water, Silver Spring, MD.

ORI, 1981. Accident Severities Experienced by Radioactive Material Packages Transported by Water, Silver Spring, MD.

Paik, J.K. and Pedersen, P.T., 1996. "Modeling of the Internal Mechanics in Ship Collisions", Ocean Engineering, Vol. 23, No. 2, pp. 107-142.

Pedersen P.T. and Zhang S., 1998. "On Impact Mechanics in Ship Collisions", Marine Structures, Vol. 11, pp. 429-449.

Rawson, C., K. Crake and A.J. Brown, 1998. "Assessing the Environmental Performance of Tankers in Accidental Grounding and Collision", presented at the SNAME Annual Meeting.

Reardon, P. and Sprung, J.L., 1996. "Validation of Minorsky's Ship Collision Model and Use of the Model to Estimate the Probability of Damaging a Radioactive Material Transportation Cask During a Ship Collision", Proceedings of the International Conference on Design and Methodologies for Collision and Grounding Protection of Ships, San Francisco.

Rosenblatt \& Son, Inc, 1975. "Tanker Structural Analysis for Minor Collision”, USCG Report, CG-D-72-76.

Sandia National Laboratories, 1998. Data and Methods for the Assessment of the Risks Associated with the Maritime Transport of Radioactive Materials Results of the SeaRAM Program Studies, SAND98-1171/2, Albuquerque, NM.

Sirkar, J. et al., 1997. "A Framework for Assessing the Environmental Performance of Tankers in Accidental Groundings and Collisions", presented at the SNAME Annual Meeting.

USCG Ship Casualty Data, 1982-1990. 